\title{
Characterisation of Somatostatin Release from the Pancreas
}

\author{
The Role of Calcium and Acetylcholine \\ K. Hermansen, S. E. Christensen, and H. Ørskov \\ Second University Clinic of Internal Medicine, Kommunehospitalet, Aarhus, Denmark
}

\begin{abstract}
Summary. The effect of calcium on somatostatin secretion was investigated in the isolated, perfused canine pancreas preparation and compared with those of acetylcholine, glucose, isoproterenol and arginine. Calcium $(5 \mathrm{mmol} / \mathrm{l})$ stimulated somatostatin release in a typical biphasic response pattern being about 5 times as potent as acetylcholine $(1 \mu \mathrm{mol} / \mathrm{l})$, arginine $(5 \mathrm{mmol} / \mathrm{l})$, and isoproterenol $(2 \mathrm{ng} / \mathrm{ml})$ while the release of insulin and glucagon in response to calcium and the other secretagogues were of the same magnitude. Somatostatin release increased progressively when perfusate calcium was increased step-wise from 0 through 1.25 and 2.5 to $5.0 \mathrm{mmol} / 1$. Calcium stimulated the secretion of somatostatin in the absence of glucose. The stimulatory effect of calcium was, however, modulated by the glucose concentration being about twice as large at $200 \mathrm{mg} / 100 \mathrm{ml}$ as at $25 \mathrm{mg} / 100 \mathrm{ml}$ glucose in the perfusion medium.
\end{abstract}

Key words: Perfused pancreas, somatostatin, insulin, glucagon, calcium, acetylcholine, glucose, isoproterenol, arginine, radioimmunoassay, dog pancreas.

Somatostatin, was isolated and synthesised by Guillemin and coworkers [1]. It soon appeared, however, that this compound is present not only in the hypothalamus, but in many other locations, such as the D-cells of the islets of Langerhans [2].

It was demonstrated that somatostatin in socalled pharmacological concentrations inhibited various exocrine and endocrine processes including insulin [3] and glucagon release [4]. The physiological significance of these many effects however, has not been established.
Recent studies have shown that many stimulators of insulin secretion such as tolbutamide [5], arginine [6], leucine [5], glucose $[5,7,8]$, pancreozymincholecystokinin [5], gastrin. [9], gastric inhibitory polypeptide [9] and secretin [9] also enhance the release of pancreatic somatostatin. As it is known that calcium ions are of principal importance for insulin $[10,11]$ and glucagon release $[12,13]$, the secretory processes being apparently triggered by a cytosolic accumulation of this cation, we decided to investigate a possible role of calcium in the secretory process of the pancreatic D-cell. The effect of calcium on somatostatin secretion by the perfused canine pancreas preparation has therefore been studied and compared with the effects of acetylcholine, glucose, arginine and isoproterenol, all established insulin secretagogues.

\section{Material and Methods}

Male mongrel dogs, fasted overnight, weighing $17-23 \mathrm{~kg}$ were used as pancreas donors. The techniques for isolation of the canine pancreas and the perfusion system has previously been described in detail [14]. In brief, the preparation consists of the pancreas and the proximal $10 \mathrm{~cm}$ of the attached duodenum. A non-recirculating medium of Krebs-Ringer bicarbonate buffer $\mathrm{pH} 7.4$ containing $40 \mathrm{~g} / 1$ dextran (molecular weight 75000 ), $2 \mathrm{~g} / 1$ bovine albumin, glutamate, fumarate, and pyruvate, each at a concentration of $5 \mathrm{mmol} / \mathrm{l}$, was pumped through the splenic and the coeliac arteries, and the total portal effluent was collected every minute. The perfusion pressure was $30-40 \mathrm{mmHg}$, and the perfusion flow was $18-20 \mathrm{ml} / \mathrm{min}$ during the experiments. Substances to be investigated were added to the basic perfusion medium through constant side-arm infusion syringes.

The pancreas was perfused for an equilibration period of 20-30 minutes. Thereafter, the substances to be studied were infused for 15 to 20 minutes allowing a similar recovery period between stimulations. The total perfusion averaged three hours. Effluent samples were collected every minute.

The following substances were used: $\mathrm{L}$-iso proterenol and L- 

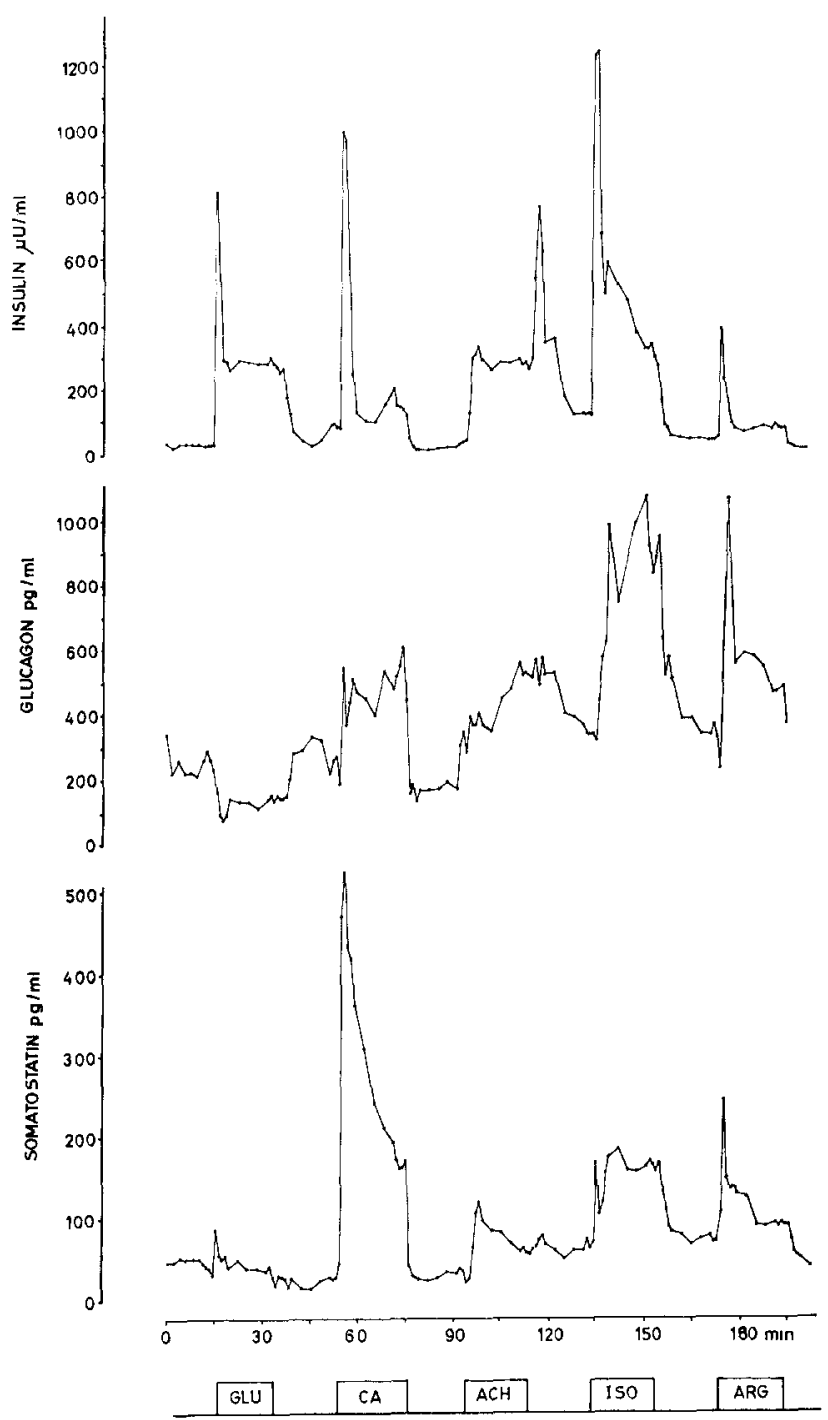

Fig. 1. Effect of 20 minute infusions of glucose (GLU) $100 \mathrm{mg} /$ $100 \mathrm{ml}$, calcium (CA) $5 \mathrm{mmol} / \mathrm{l}$, acetylcholine (ACH) $1 \mu \mathrm{mol} / \mathrm{l}$, isoproterenol (ISO) $2 \mathrm{ng} / \mathrm{ml}$ and arginine (ARG) $5 \mathrm{mmol} / 1$ on insulin, glucagon and somatostatin release. The basal perfusate contained glucose $100 \mathrm{mg} / 100 \mathrm{ml}$ and calcium $1.3 \mathrm{mmol} / \mathrm{l}$

arginine hydrochloride (Sigma Chemical Comp. St. Louis, Mo.) Acetylcholine chloride, calcium chloride (Merck, Darmstadt).

\section{Radioimmunoassays}

Rabbits were immunised by subcutaneous injections of equal volumes of cyclic somatostatin conjugated with carbodiimide to thyroglobulin and complete Freund's adjuvant [15]. After 5 to 9 booster injections at monthly intervals useable antisera for radioimmunoassay were raised in all of three rabbits, working titres being $1: 2000,1: 4000$, and $1: 8000$. Tyr ${ }^{1}$-somatostatin was iodinated with ${ }^{125} \mathrm{I}$ by a modification of the chloramine $T$ technique according to Harris et al. [16]: $2 \mu \mathrm{g} \mathrm{TYR}^{1}$-somatostatin was added to $2 \mathrm{mCi}^{125} \mathrm{I}$, Amersham IMS-3, and $4 \mu \mathrm{g}$ chloramine $\mathrm{T}$ for 60 seconds. Metabisulphite reduction was omitted, instead the reaction was terminated with the addition of $400 \mu \mathrm{g}$ bovine serum albumin.

The crude iodination products were purified on Sephadex $G 25$ fine column chromatography $(10 \mathrm{~mm} \times 600 \mathrm{~mm})$ using $0.1 \mathrm{~mol} / \mathrm{l}$ acetic acid with a $1 \mathrm{~g} / 1$ gelatine product $\left(\right.$ Haemaccel ${ }^{\mathrm{R}}$, Behringwerke $A G$ ) for elution. In our hands (unpublished), mono-and diiodinated somatostatin always appeared after the total volume as peaks no 3 and 4, corresponding to 3-4 and 5-6 times the void volume.

The specific radioactivity was approximately 1000 and $2000 \mu \mathrm{Ci} / \mu \mathrm{g}$ for mono- and diiodinated somatostatin respectively. The evidence that these fractions were indeed mono- and diiodinated somatostatin without contamination of unlabelled antigen was based primarily on the facts that they competed in a parallel fashion in the radioimmunoassay and that they showed approximate maximum specific activities for mono- and diiodinated specimens when calculated according to the self-displacement principle [17]. It is also known that the elution on Sephadex of other iodinated compounds is increasingly delayed with increasing number of iodine atoms incorporated [17]. Approximately $85 \%$ of the labelled compounds were bound in moderate excess of antibody and there was neither appreciable loss of specific activity, immunoreactivity nor increase in storage damage during two months after iodination. The antiserum showed no cross reaction with insulin, glucagon, pancreatic polypeptide (PP) or vasoactive intestinal polypeptide (VIP).

For the assay, $100 \mu \mathrm{l}$ antiserum (SEC I) in a titre of $1: 8000$ was added to incubation tubes $(9 \mathrm{~mm} \times 50 \mathrm{~mm})$, followed by $100 \mu \mathrm{I}$ of standards or perfusion buffer. After 24 hours incubation $100 \mu{ }^{125} \mathrm{I}$ monoiodinated somatostatin $(150 \mathrm{pg} / \mathrm{ml})$ was added and incubated for a further $24 \mathrm{~h}$.

Separation of free from antibody-bound labelled antigen was achieved by wick chromatography with $3 \mathrm{MM}$ paper wicks (Whatman) as was the case for pancreatic glucagon and insulin [18]. "Damage" of labelled antigen was measured in individual tubes without antibody and appropriate corrections made [19]. Incubation damage was only $2-4 \%$ when the assay was used for samples of the effluent from the isolated pancreas.

For dilution of antibody and labelled somatostatin, $0.04 \mathrm{~mol} / \mathrm{l}$ phosphate buffer, $\mathrm{pH} 8$, with $0.6 \mathrm{mmol} / 1$ sodium merthiolate and $2 \mathrm{~g} / \mathrm{l}$ bovine serum albumin was used, while standards were diluted in the perfusion buffer. Detection limit was $10 \mathrm{pg} / \mathrm{ml}$ or $1 \mathrm{pg} /$ tube.

\section{Results}

\section{Effects of Calcium, Acetylcholine, Glucose, Isoproterenol and Arginine}

The effect of calcium on somatostatin release was studied by comparing it to the effects of acetylcholine, glucose, arginine, and isoproterenol in 20 minute sequential infusion periods. The basal perfusion medium had a glucose concentration of $100 \mathrm{mg} /$ $100 \mathrm{ml}$, and a calcium concentration of $1.3 \mathrm{mmol} / 1$.

The four secretagogues were infused at concentrations expected to give similar insulin release to that found with $5 \mathrm{mmol} / \mathrm{l}$ calcium. Figure 1 shows the results of one such experiment. Infusion of glucose at a concentration of $100 \mathrm{mg} / 100 \mathrm{ml}$ to result in a final concentration of $200 \mathrm{mg} / 100 \mathrm{ml}$ stimulated somatostatin and insulin release and suppressed glucagon release as expected. The other secretagogues stimulated release of somatostatin, insulin and glucagon.

The somatostatin release pattern was very similar to that of insulin, with immediate increases and 


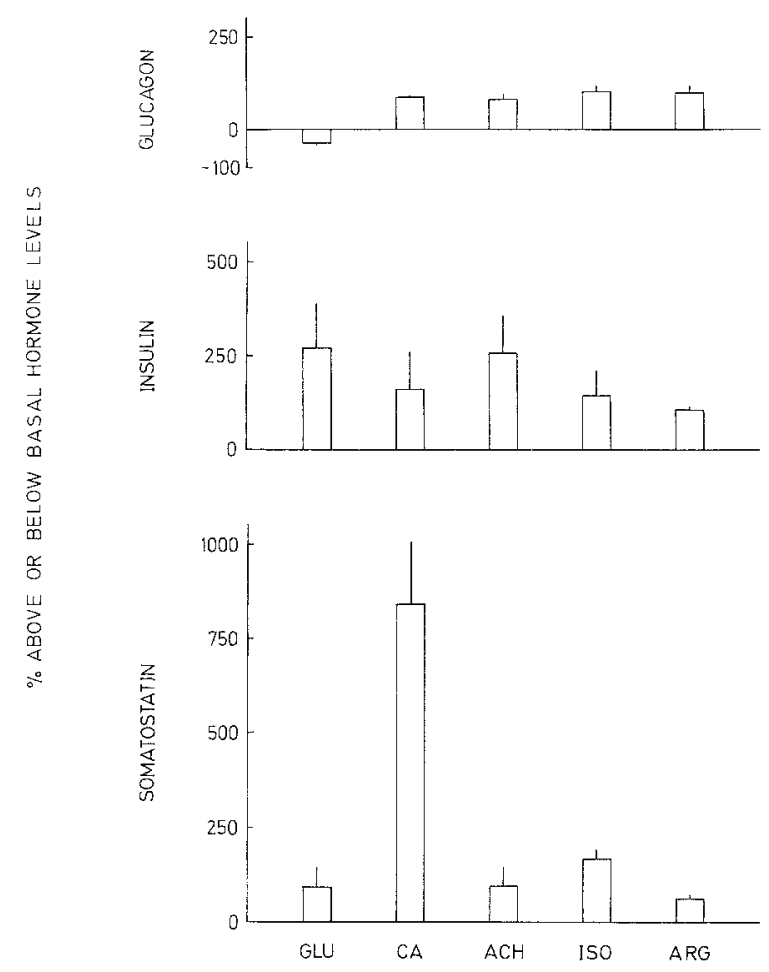

Fig. 2. Average increases (mean \pm SEM) in per cent above basal hormone levels in three experiments (see Fig. 1). The increase was calculated as the mean of the hormone values during the entire stimulation period minus the average basal level obtaining during the five minutes immediately before stimulation

decreases in response to infusion and withdrawal of the stimuli.

The effect of the five secretagogues on insulin secretion was as expected, with the calcium effect of the same order of magnitude as that of acetylcholine, glucose, arginine and isoproterenol (Fig. 2).

The effect of calcium on somatostatin release was, however, different, being about five times higher than that obtained by the four secretagogues used for comparison.

\section{Effect of Variations in Calcium Concentration on the Pancreatic Somatostatin Release}

The effect of increasing calcium concentration was investigated on 5 occasions during 3 perfusion experiments. During perfusion with a constant concentration of glucose of $100 \mathrm{mg} / 100 \mathrm{ml}$, perfusate calcium was increased step-wise for 15 minutes periods from 0 through 1.25 and 2.5 to $5.0 \mathrm{mmol} / \mathrm{l}$. This is illustrated in Figure 3. Results are given as means \pm SEM $(n=5)$. On all five occasions the gradual increase in the calcium concentration caused a dose-dependent

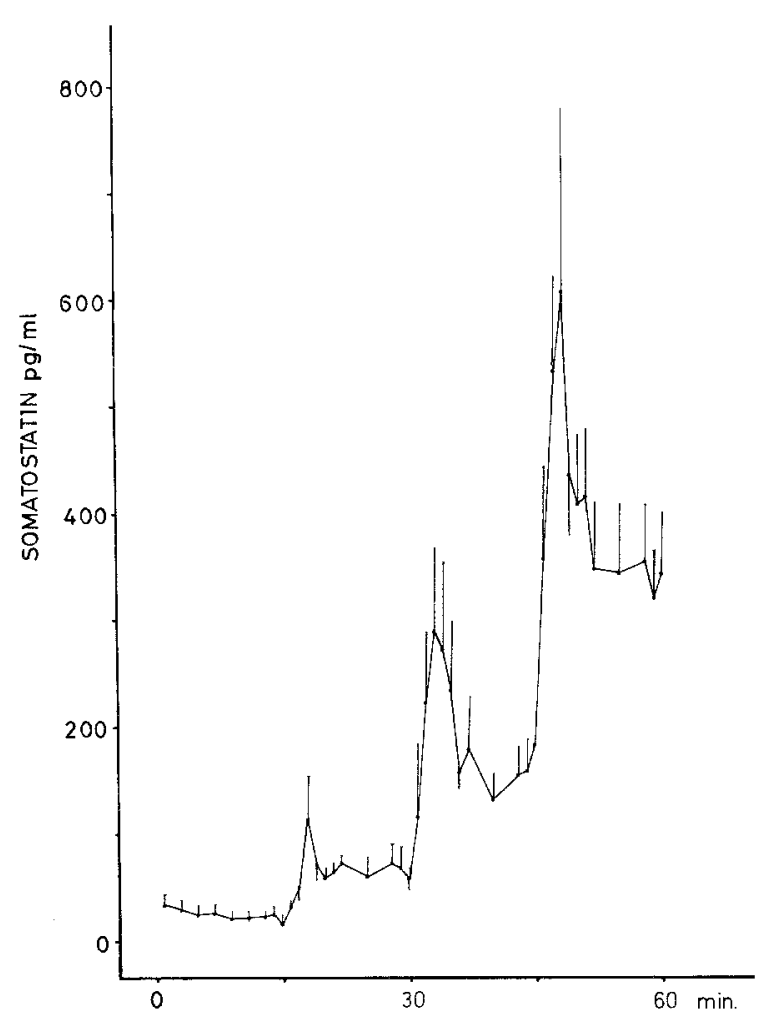

Ca mmol/l 5

Fig. 3. The effect on somatostatin release of step-wise increases in perfusate calcium: $0 ; 1.25 ; 2.5$ and $5.0 \mathrm{mmol} / \mathrm{l}$ at a constant glucose concentration of $100 \mathrm{mg} / 100 \mathrm{ml}$. Mean \pm SEM of 5 experiments in 3 perfusions

increase in the secretion of somatostatin. The somatostatin responses were again biphasic.

\section{Effect of Increase in Perfusate Calcium at Zero, at Low and High Concentrations of Glucose}

At a calcium concentration of $1.3 \mathrm{mmol} / \mathrm{l}$, basal somatostatin and insulin levels were low and basal glucagon was high during perfusion with a glucose depleted medium (Fig. 4). When the glucose concentration in the perfusing medium was increased from 0 to $25 \mathrm{mg} / 100 \mathrm{ml}$, glucagon release was slightly reduced, whereas somatostatin and insulin release remained unchanged. The somatostatin and insulin responses to an increase in perfusate glucose from 25 to $200 \mathrm{mg} / 100 \mathrm{ml}$ were biphasic, whereas glucagon was further suppressed to low levels.

A 15 minutes increase of the calcium concentration from 1.3 to $6.3 \mathrm{mmol} / 1$ stimulated somatostatin, insulin as well as glucagon. This occurred during perfusion with zero, low $(25 \mathrm{mg} / 100 \mathrm{ml})$ as well as with high $(200 \mathrm{mg} / 100 \mathrm{ml})$ glucose concentrations. The responses obtained were modified by the glucose 

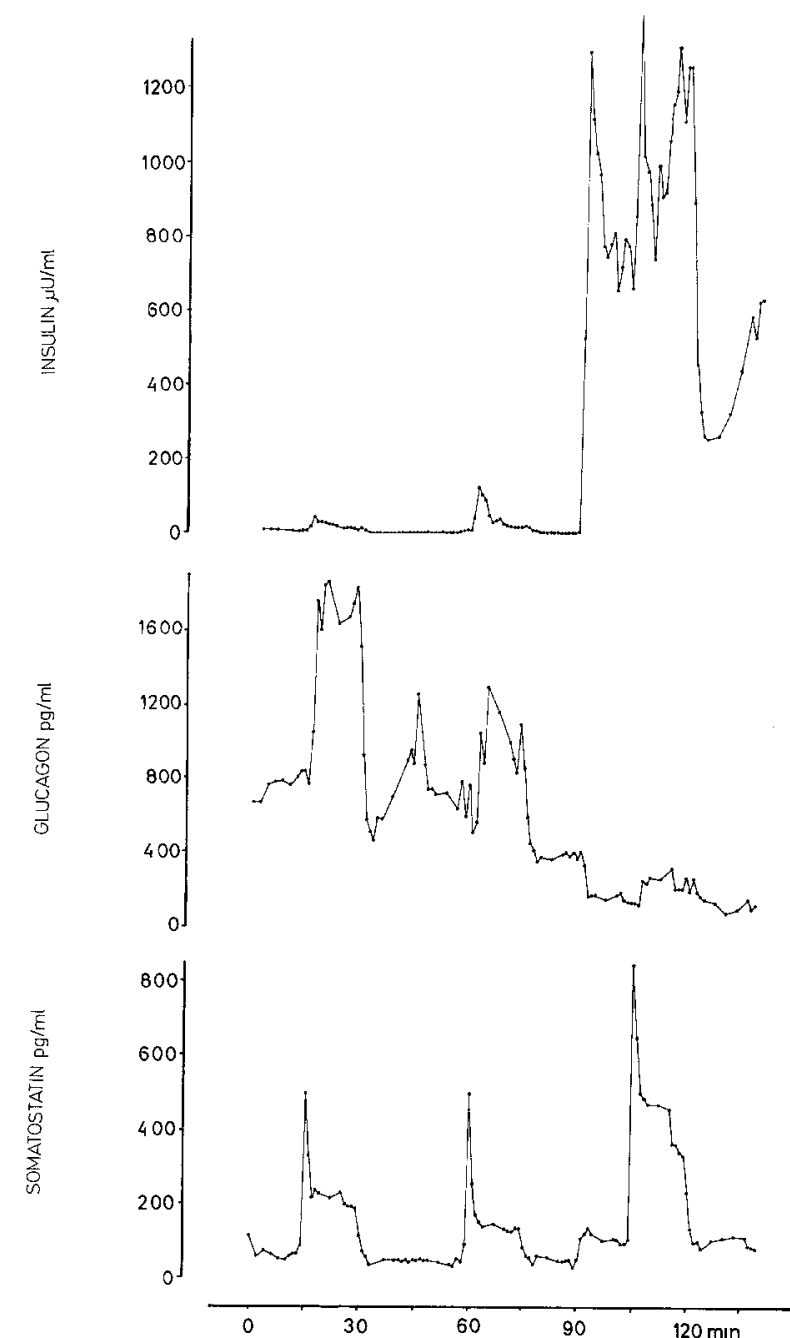

GLUCOSE $\mathrm{mg} / 100 \mathrm{ml} 200$

CALCIUM minol/l

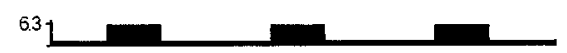

Fig. 4. The effect of the glucose level: $0 ; 25$ and $200 \mathrm{mg} / 100 \mathrm{ml}$ on the hormone responses to an increase in calcium concentration from 1.3 to $6.3 \mathrm{mmol} / \mathrm{l}$. One representative experiment out of 4

concentrations present: higher somatostatin and insulin and lower glucagon responses were obtained at high rather than at low glucose concentrations (Fig. 4). There was no difference in the magnitude of the calcium-induced somatostatin response at zero or low $(25 \mathrm{mg} / 100 \mathrm{ml})$ glucose concentrations.

The average results of 4 experiments are given in Table 1.

\section{Discussion}

The experiments reported here have for the first time demonstrated that calcium stimulates secretion of pancreatic somatostatin and that the calcium-induced

secretion is much greater than that achieved by acetylcholine, glucose, arginine, and isoproterenol when concentrations were used which gave similar responses of insulin and glucagon. The stimulatory effect of calcium on somatostatin secretion was dosedependent and it was modified by glucose, being more pronounced at high than at a low glucose concentration. It is noteworthy that calcium stimulated the secretory activity of somatostatin, insulin and glucagon in the absence of glucose. The results suggest that calcium plays an important role for the secretory process of the pancreatic $\mathrm{D}$ cell as already shown for the A $[12,13]$ and $B$ cells $[10,11]$.

The possible contribution of somatostatin from the duodenal remnant in preparations like the present one has been discussed by Ipp et al. [9]. Studies from this laboratory have shown that it is negligible since somatostatin release during calcium stimulation remained unaltered when the duodenum was excluded by clamping (K. Hermansen: Unpublished observations).

Our finding that glucose has a stimulatory effect on somatostatin release is in agreement with other recent reports $[5,7,8]$. In addition it has been reported that different amino acids $[5,6]$ stimulate secretion of somatostatin and this is confirmed in this study with respect to arginine.

In a study on possible sympathetic and parasympathetic control of somatostatin release from the pancreas Samols et al. [20] investigated the effect of adrenergic and cholinergic agonists. They found that the $\alpha$-adrenergic agonism of L-epinephrine inhibited somatostatin secretion i.e. epinephrine with prior propanolol administration inhibited secretion of somatostatin and that the $\beta$-adrenergic agonism of isoproterenol caused a stimulation of somatostatin secretion. In our experiments the same effect of isoproterenol was seen and we were also able to demonstrate a stimulatory effect of acetylcholine $(1 \mu \mathrm{mol} / \mathrm{l})$. This last mentioned result is at variance with preliminary results of Samols et al. [20] who found that higher concentrations of acetylcholine (25 and $50 \mu \mathrm{mol} / \mathrm{l})$ stimulated secretion of insulin and glucagon but mildly suppressed somatostatin release from pancreas. The reason for these differing results is unknown.

It is possible to regard somatostatin either as a circulating hormone or as a substance exerting paracrine effects on the adjacent A-, B- and PP-cells in the pancreatic islets or as a peptidergic neurotransmitter [21]. One major question concerns the purpose, if any, of the anatomical juxtaposition of the A, $\mathrm{B}, \mathrm{PP}$, and D cells in the islets of Langerhans. One approach would be to ascertain if the extracellular concentrations of somatostatin in the islets are suffi- 
Table 1. The effect of glucose on the calcium mediated pancreatic hormone release

\begin{tabular}{|c|c|c|c|c|c|c|c|}
\hline \multirow[t]{2}{*}{ EXP } & \multirow[t]{2}{*}{$\begin{array}{l}\text { Glucose } \\
\mathrm{mg} / 100 \mathrm{ml}\end{array}$} & \multicolumn{2}{|c|}{$\begin{array}{l}\text { Somatostatin } \\
\mathrm{pg} / \mathrm{ml}\end{array}$} & \multicolumn{2}{|c|}{$\begin{array}{l}\text { Glucagon } \\
\mathrm{pg} / \mathrm{ml}\end{array}$} & \multicolumn{2}{|l|}{$\begin{array}{l}\text { Insulin } \\
\mu \mathrm{U} / \mathrm{ml}\end{array}$} \\
\hline & & A & B & A & $\mathrm{B}$ & A & B \\
\hline & 0 & $52 \pm 5$ & 229 & $731 \pm 19$ & 421 & $12 \pm 1$ & 11 \\
\hline \multirow[t]{3}{*}{1} & 25 & $41 \pm 3$ & 213 & $536 \pm 26$ & 242 & $17 \pm 4$ & 15 \\
\hline & 200 & $150 \pm 1$ & 798 & $401 \pm 27$ & 135 & $1124 \pm 11$ & 353 \\
\hline & 0 & $63 \pm 3$ & 173 & $807 \pm 16$ & 750 & $6 \pm 0$ & 15 \\
\hline \multirow[t]{3}{*}{2} & 25 & $47 \pm 4$ & 136 & $693 \pm 34$ & 258 & $5 \pm 1$ & 39 \\
\hline & 200 & $107 \pm 3$ & 347 & $163 \pm 10$ & 78 & $723 \pm 20$ & 392 \\
\hline & 0 & $29 \pm 2$ & 68 & $296 \pm 4$ & 189 & $3 \pm 0$ & 2 \\
\hline \multirow[t]{3}{*}{3} & 25 & $20 \pm 4$ & 85 & $197 \pm 8$ & 98 & $2 \pm 1$ & 9 \\
\hline & 200 & $55 \pm 4$ & 112 & $40 \pm 2$ & 24 & $156 \pm 7$ & 45 \\
\hline & 25 & $35 \pm 1$ & 166 & $165 \pm 5$ & 384 & $3 \pm 1$ & 4 \\
\hline 4 & 200 & $73 \pm 1$ & 381 & $75 \pm 3$ & 256 & $245 \pm 8$ & 169 \\
\hline
\end{tabular}

Glucose 0,25 or $200 \mathrm{mg} / 100 \mathrm{ml}$ was infused for 45 minutes. After 15 minutes calcium was increased from 1.3 to $6.3 \mathrm{mmol} / 1 \mathrm{over} 15$ minutes. The effect of zero glucose was not investigated in experiment 4

The hormone response (column B) was calculated as the average increase of the entire stimulation period over the mean concentration during the last 5 minutes preceeding calcium stimulation (column A, mean \pm SEM). One experiment is shown in Figure 4

cient to modulate insulin, glucagon or PP secretion. It seems as if they are: as little as $50 \mathrm{pg}$ somatostatin per $\mathrm{ml}$ added to the influx perfusion medium suppresses secretion of insulin and glucagon (Unpublished observation). This concentration is easily achieved in the efflux from the isolated pancreas in response to physiological stimuli. It must be considered that the hormone concentrations we measure in the effluent are much lower than those found in veins draining the islets of Langerhans as a result of dilution by venous contribution from all of the exocrine pancreas. Therefore extracellular concentrations of somatostatin are seemingly available in the islets to allow a paracrine effect on the A, B and PP cells.

On many occasions, for example after the five stimuli used in this study, somatostatin release occurs together with insulin and glucagon secretion and one is fced with the paradox that these do not seem to be inhibited by the simultaneous secretion of somatostatin. On the other hand one can as yet only speculate on the magnitude of the insulin and glucagon responses if the somatostatin response had not been present.

Our findings suggest that somatostatin release is triggered by the accumulation of calcium ions at some critical site in the D-cell and that this process is modulated by the glucose concentration. Moreover, the effect of acetylcholine and isoproterenol is consistent with a direct role of the parasympathetic and the sympathetic nervous system. The physiological significance of the location of the D-cell in the islets of Langerhans has not been established, but it seems plausible that secreted somatostatin contributes to the regulation of insulin, glucagon and pancreatic polypeptide secretion.

Acknowledgements. The invaluable advice on the iodination procedure given to us by Dr. Roger Unger, Veterans Administration Hospital, Dallas, Texas, is gratefully acknowledged. Cyclic somatostatin for immunisation and standards was kindly donated by Norman Grant, Wyeth Laboratories, Philadelphia, Pensylvania; and Roger Guillemin, Salk Institute, La Jolla, California, generously gave us $\mathrm{Tyr}^{1}$-somatostatin for the iodination. Lise Heding, NOVO Research Lab., Copenhagen, is cordially thanked for a generous gift of specific pancreatic glucagon antiserum. Inga Bisgaard, Bente Jacobsen, Karen Just, Inge Ploug and Birthe Videbæk are thanked for their expert technical assistance and Anette Larsen for typing the manuscript.

This work was supported by the Danish Medical Research Council (no 512-8374 and 512-6650), P. Carl Petersen Foundation and a NOVO research grant

\section{References}

1. Brazeau, P., Vale, W., Burgus, R., Ling, N., Butcher, M., Rivier, J., Guillemin, R.: Hypothalamic polypeptide that inhibits the secretion of immunoreactive pituitary growth hormone. Science 179, 77-79 (1973)

2. Luft, R., Efendic, S., Hökfelt, T., Johansson, O., Arimura, A.: Immunohistochemical evidence for the localization of somatostatin-like immunoreactivity in a cell population of pancreatic islets. Med. Biol. 52, 428-430 (1974)

3. Alberti, K. G. M. M., Christensen, S. E., Iversen, J., SeyerHansen, K., Christensen, N. J., Hansen, Aa. P., Lundbæk, K., Ørskov, H.: Inhibition of insulin secretion by somatostatin. Lancet 1973 II, 1299-1301

4. Iversen, J.: Inhibition of pancreatic glucagon release by somatostatin: In vitro. Scand. J. Clin. Lab. Invest. 33, 125-129 (1974) 
5. Ipp, E., Dobbs, R. E., Arimura, A., Vale, W., Harris, V., Unger, R. H.: Release of immunoreactive somatostatin from the pancreas in response to glucose, amono-acids, pancreozymin - cholecystokinin, and tolbutamide. J. Clin. Invest. 60, $760-765$ (1977)

6. Patton, G. S., Ipp, E., Dobbs, R. E., Vale, W., Orci, L., Unger, R. H.: Response of pancreatic immunoreactive somatostatin to arginine. Life Sci. 19, 1957-1960 (1976)

7. Schauder, P., McIntosh, C., Arends, J., Arnold, R., Frerichs, H., Creutzfeldt, W.: Somatostatin and insulin release from isolated rat pancreatic islets stimulated by glucose. FEBS Lett. 68, 225-227 (1976)

8. Weir, G. C., Samols, E., Ramseur, R., Day, J. A., Patel, Y. C.: Influence of glucose and glucagon upon somatostatin secretion from the isolated, perfused canine pancreas. Clin. Res. 25, 403A (1977)

9. Ipp, E., Dobbs, R. E., Arimura, A., Vale, W., Unger, R. H.: The effects of gastrin, gastric inhibitory polypeptide, secretin and the octapeptide of cholecystokinin upon immunoreactive somatostatin release by the perfused canine pancreas. J. Clin. Invest. 60, 1216-1219 (1977)

10. Milner, R. D. G., Hales, C. N.: The role of calcium and magnesium in insulin secretion from rabbit pancreas studies in vitro. Diabetologia 3, 47-49 (1967)

11. Grodsky, G. M., Bennett, L. L.: Cation requirements for insulin secretion in the isolated, perfused pancreas. Diabetes $\mathbf{1 5}$, 910-913 (1966)

12. Iversen, J., Hermansen, K.: Calcium, glucose and glucagon release. Diabetologia 13, 297-303 (1977)

13. Hermansen, K., Iversen, J.: Effect of verapamil on pancreatic glucagon release from the isolated, perfused canine pancreas. Scand. J. Clin. Lab. Invest. 37, 139-142 (1977)

14. Iversen, J., Miles, D. W.: Evidence for a feed-back inhibition of insulin on insulin secretion in the isolated perfused canine pancreas. Diabetes 20, 1-9 (1971)
15. Arimura, A., Sato, H., Coy, D. H., Schally, A. V.: Radioimmunoassay for GH-release inhibiting hormone. Proc. Soc. Exp. Biol. Med. 148, 784-789 (1975)

16. Harris, V., Conlon, J.M., Srikant, C. B., McCorkle, K., Schusdziarra, V., Ipp, E., Unger, R. H.: Measurements of somatostatin-like immunoreactivity in plasma. Clin. Chim. Acta 87, 275-283 (1978)

17. Weeke, J., Ørskov, H.: Synthesis of ${ }^{125}$ I monolabelled 3,5,3'triiodothyronine and thyroxine of maximum specific activity for radioimmunoassay. Scand. J. Clin. Lab. Invest. 32, $357-360(1973)$

18. Ørskov, H., Thomsen, H. G., Yde, H.: Wick chromatography for rapid and reliable immunoassay of insulin, glucagon and growth hormone. Nature 219, 193-195 (1968)

19. Ørskov, H., Seyer-Hansen, K.: Measurement of and correction for incubation damage in radioimmunoassay. Eur. J. Clin. Invest. 4, 207-211 (1974)

20. Samols, E., Weir, G. C., Ramseur, R., Day, J. A., Patel, Y. C. Modulation of pancreatic somatostatin by adrenergic and cholinergic agonism and by hyper- and hypoglycemic sulfonamides. Metabolism 27 [Suppl. I], 1219-1221 (1978)

21. Luft, R., Efendic, S., Hökfelt, T.: Somatostatin - Both hormone and neurotransmitter? Diabetologia 14, 1-13 (1978)

Received: July 10, 1978, and in revised form: October 17, 1978

K. Hermansen, M. D.

Second University Clinic of Internal Medicine

Kommunehospitalet

DK-8000 Aarhus C

Denmark 